\title{
Research Article \\ Effect of Coupling Agent on the Properties of Polymer/Date Pits Composites
}

\author{
Fares D. Alsewailem and Yazeed A. Binkhder \\ Petrochemicals Research Institute, King Abdulaziz City for Science and Technology, P.O. Box 6086, Riyadh 11442, Saudi Arabia \\ Correspondence should be addressed to Fares D. Alsewailem; fsewailm@kacst.edu.sa
}

Received 7 October 2013; Accepted 17 December 2013; Published 9 January 2014

Academic Editor: Nikhil Gupta

Copyright (C) 2014 F. D. Alsewailem and Y. A. Binkhder. This is an open access article distributed under the Creative Commons Attribution License, which permits unrestricted use, distribution, and reproduction in any medium, provided the original work is properly cited.

\begin{abstract}
The morphology of the fracture surfaces of polymer/date pits composites was investigated. Polymers used in this study were high density polyethylene (HDPE) and polystyrene (PS). Date pits in the form of granules were two types of date pits: khlaas (K) and sekari (S). Two coupling agents, diphenylmethane- $44^{\prime}$-diisocyanate (DPMI) and ethylene propylene grafted with malice anhydride (EP-g-MA), were used to ease the incorporation of date pit particles into polymer matrix. The SEM micrographs of the neat composites, that is, with no coupling agents, showed coarse morphology with bad dispersion, adhesion, and distribution of date pit particles within the polymer matrix. On the other hand, PS100/K composites coupled with DPMI and EP-g-MA had reasonable dispersed phase size with good distribution and adhesion to the composite matrix which in turn improve the mechanical properties of the resulted polymer/date pits composites.
\end{abstract}

\section{Introduction}

Biomass in the form of agricultural waste such as wheat straw, corncob, and rice husk offers feasible and environmentally benign filling materials for polymeric materials. One of these biofillers which is abundantly available in the Arabian peninsula is date pits; a byproduct of palm trees (Phoenix dactylifera L.). One date pit may contain up to $10 \%$ oils, minerals (e.g., potassium), and fibers (>6.4\%).

Incorporating a cost-effective filler in a polymeric matrix will only be feasible if it does not drastically alter the matrix main characteristics such as mechanical properties. The determinant issue here is the compatibility between the interfaces of a biofiller and the polymer matrix. This is important in order to have property-stable composite system. For this reason, various compatibilizers or coupling agents were suggested by some studies in the past to formulate efficient biocomposites based on polymer matrices [1-4]. Wang et al. [1] have shown that incorporating DPMI as a coupling agent for the composites of wheat straw/polyethylene (PE) increased its modulus significantly. Wood fiber/polypropylene composites with good mechanical properties may be obtained by using modified coupling agent containing isocyanate functional group [4]. Maleated polyolefins such as $\mathrm{m}-\mathrm{PE}$ and polypropylene (m-PP) were found efficient compatibilizers for improving mechanical properties of PE and PP filled with wood fibers [2, 3].

Studies on polymer/date pits composites are sparse $[5,6]$. In our previous study [5], we reported the formulation of the noncompatibilized polymer/date pits composites based on high density polyethylene (HDPE) and polystyrene (PS). We concluded that while tensile strength (TS) of the polymer/ date pits, especially that of HDPE/date pits composites, was not greatly affected by the presence of date pit particles, the Izod impact strength (IIS) of such composite system deteriorated to greater extent upon the incorporating of date pit particles into the polymer matrix. We emphasized that this can be attributed to the weakness of the interface of the composites due to the lack of proper compatibility, that is, the presence of suitable coupling agent. Therefore, the aim of the current study was to investigate the influence of some coupling agents on the properties of polymer/date pits composites. 


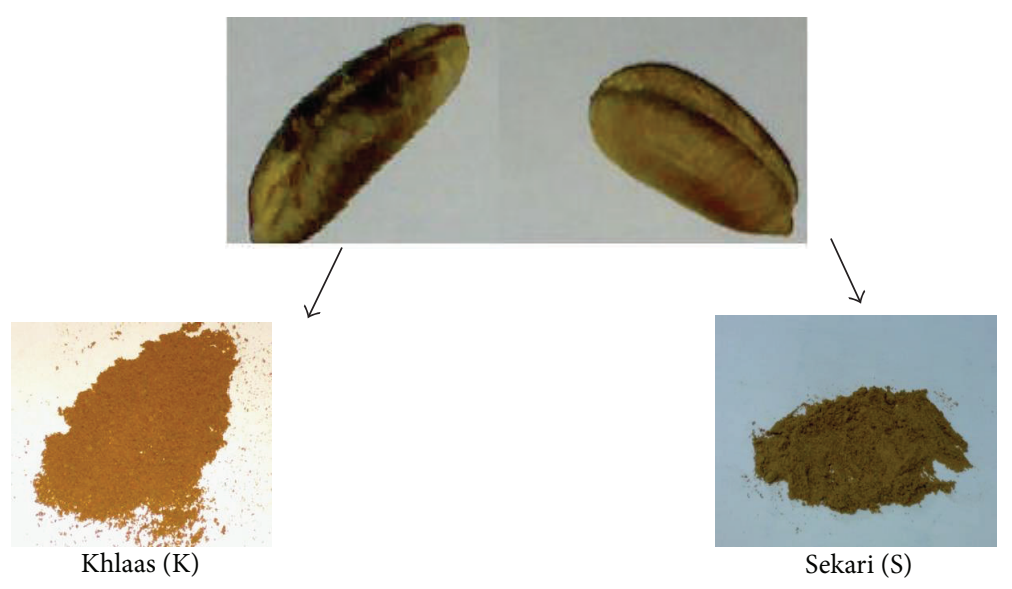

(a)

(b)

FIGURE 1: Photograph of date pits used in this study. (a) Khlaas and (b) sekari.

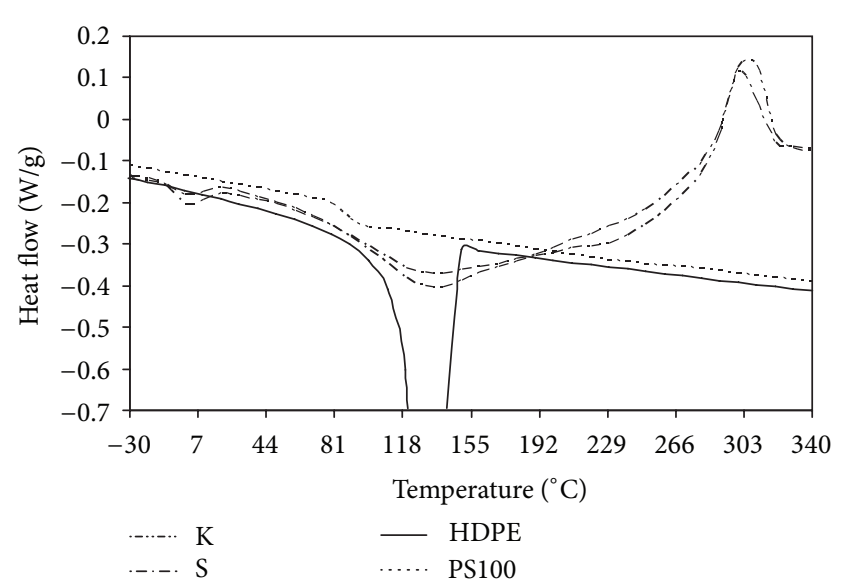

FIGURE 2: DSC scans for all neat materials.

\section{Experimental}

\subsection{Materials Used}

2.1.1. Date Pits. Two locally grown date pits-khlaas (K) and sekari (S)-were used in this study. A photograph of these two date pits is shown in Figure 1. A khlaas date pit has higher percentages of aluminum and calcium than those found in a sekari date pit [7]. On the other hand, some other minerals such as magnesium and potassium may be found at high contents in sekari date pits but not in khlaas date pits [7].

2.1.2. Matrix Materials. Polymers used in this study were a blow molding grade HDPE and a general purpose polystyrene PS100 with melt flow index (MFI) that equals $13 \mathrm{~g} / 10 \mathrm{~min}$. These two polymers are courtesy of Saudi Basic Industries Corporation (SABIC) in Riyadh, Saudi Arabia.
2.1.3. Coupling Agents. Two coupling materials were used as follows. The first was diphenylmethane- $44^{\prime}$-diisocyanate (DPMI) as used before for agrowaste/polymer composites [1]. The second coupling material was ethylene propylene grafted with maleic anhydride (EP-g-MA, Exxelor VA 1803) with a glass transition temperature $\mathrm{Tg}$ of $-57^{\circ} \mathrm{C}$.

\subsection{Procedure}

2.2.1. Preparing Date Pits. Khlaas and sekari date pits were ground to a particle size of $0.15 \mathrm{~mm}$ as described in our previous study [5].

2.2.2. Preparing Polymer-Date Pits Composites. Preparation of HDPE and PS100 with K and S date pits was given elsewhere [5]. DPMI and EP-g-MA were added to the PS100/K (70/30) wt $\%$ at up to $5 \mathrm{~g}$ and $1 \mathrm{~g}$, respectively, per 100 and 6 grams of the neat composite (i.e., $30 \mathrm{wt} \% \mathrm{~K} / \mathrm{PS} 100)$. The blends were melt mixed for $10 \mathrm{~min}$ and then injected into a mold for making tensile and impact samples according to the dimensions of ASTM D 1708 and ASTM D 256, respectively.

2.2.3. Mechanical Testing. Tensile strength and Izod impact strength in accordance with ASTM D 1708 and ASTM D 256 , respectively, were conducted to assess the mechanical stiffness and toughness of the prepared date pits/HDPE and PS100 composites. Tinius Olsen pendulum impact tester (IT 504) with a total capacity of energy that equals $7 \mathrm{~J}$ was used to measure notched Izod impact strength of the polymer/ date pits composites. Automatic notcher equipped with a very sharp blade that can provide a notch in accordance with ASTM D 265 was used to notch the sample bars. Tensile strength measurements were carried out by using a Hounsfield universal testing machine, model H5KS, using $5 \mathrm{KN}$ load cell. 


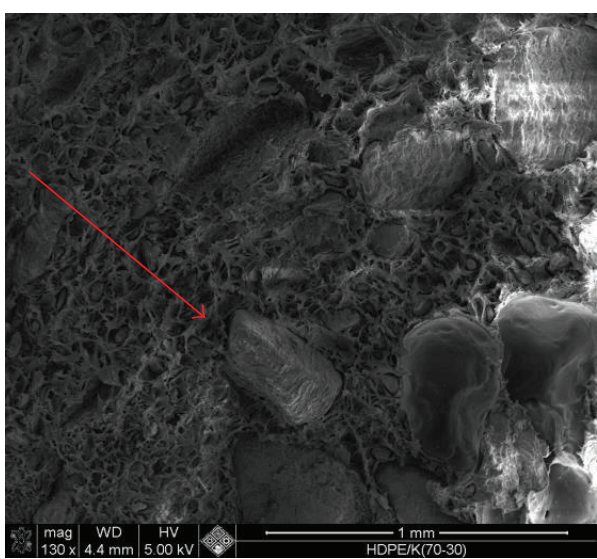

(a)

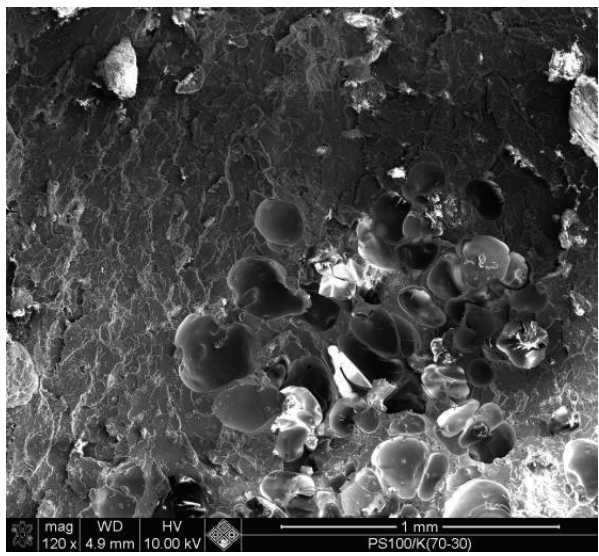

(c)

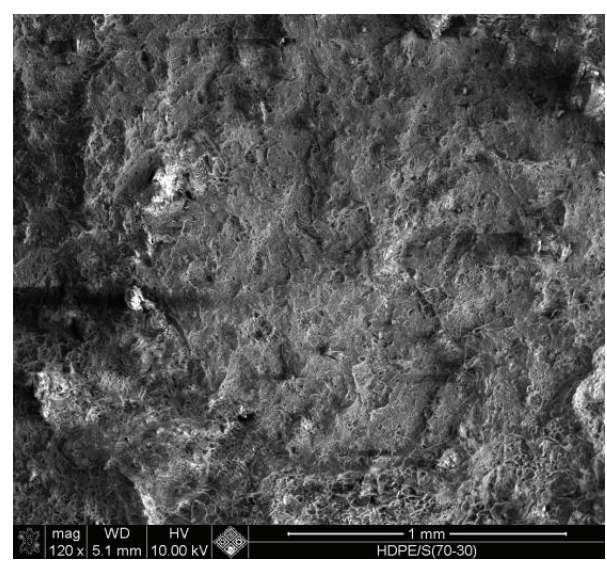

(b)

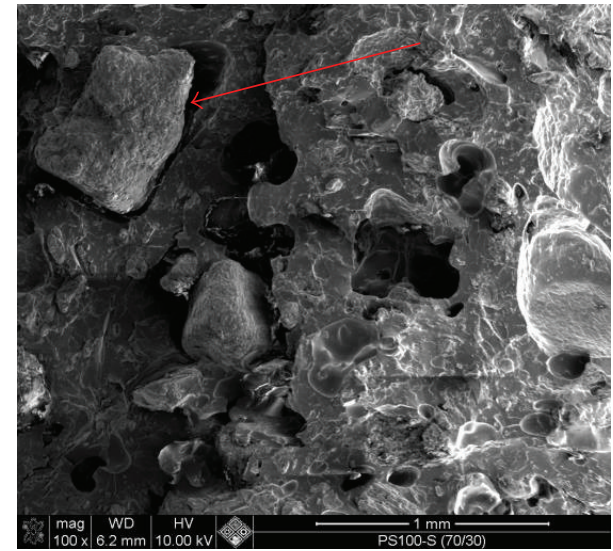

(d)

FIGURE 3: SEM micrographs of the fracture surfaces of the Izod samples for the composites at $30 \mathrm{wt} \%$ date pits loading. Images were taken at low magnification (>100x), (a) HDPE/K, (b) HDPE/S, (c) PS100/K, and (d) PS100/S.

2.2.4. Thermal Testing. A differential scanning calorimetry DSC (type TA-Q10) was used to study the thermal behavior of date pits and neat polymer. Samples ranging from 10 to $15 \mathrm{mg}$ of the composites with various loadings of date pits were heated twice up to $200^{\circ} \mathrm{C}$ at a heating rate of $10^{\circ} \mathrm{C} / \mathrm{min}$. In addition, neat polymers and date pits were tested separately by DSC at a temperature range of -30 to $340^{\circ} \mathrm{C}$.

2.2.5. Morphology of the Composites. The fracture surfaces of the Izod samples were examined by the scanning electron microscope, SEM (FEI, model NNL 200), and the scanning probe microscope, SPM (NT-MDT, solver next NSGO1-A series).

\section{Results and Discussion}

Figure 2 shows the DSC scans for the neat polymers, HDPE and PS100, and the two types of date pits, $\mathrm{K}$ and S, used in this study. The melt peak of HDPE is not completely shown, because we wanted to clearly show the transitions and peaks of other materials, that is, PS100, K, and S. Both date pits, $\mathrm{K}$ and $\mathrm{S}$, exhibited similar thermal behavior with distinct endothermic peak at approximately $0^{\circ} \mathrm{C}$, probably due to oil or water crystals melting [8], and a broad endothermic peak at onset and peak maximum of $85^{\circ} \mathrm{C}$ and $130^{\circ} \mathrm{C}$, respectively. Finally, there is a distinctive exothermic peak in the range from $290^{\circ} \mathrm{C}$ to $320^{\circ} \mathrm{C}$.

The morphology of the fracture surfaces of the Izod specimens of the composites was examined and representative SEM micrographs are given in Figures 3-6. Figure 3 shows that even at very low magnification (100-130x) of SEM imaging, the date pits domain appeared as a large chunk with irregular shape morphology. Figure 4 shows the morphology of the fracture surfaces of the HDPE/K composites at 10 , 20, and $30 \mathrm{wt} \%$ date pits. In Figure 4, one can see the poor adhesion between date pits, K particles, and HDPE matrix. It must be recalled here that HDPE is a very tough material that is unbreakable in a notched IIS, and despite this fact, we have seen how a small quantity, $5 \mathrm{wt} \%$, of date pits pronouncedly reduced its toughness [5]. Cavitations as a response to energy absorption to break the material were clearly seen in Figure 4; however, in the absence of compatibility between HDPE and date pits particles as date pits particles were debonded out of HDPE matrix, a weak interface was created and led to lower toughness. Figure 5 gives the morphology of the fractured 


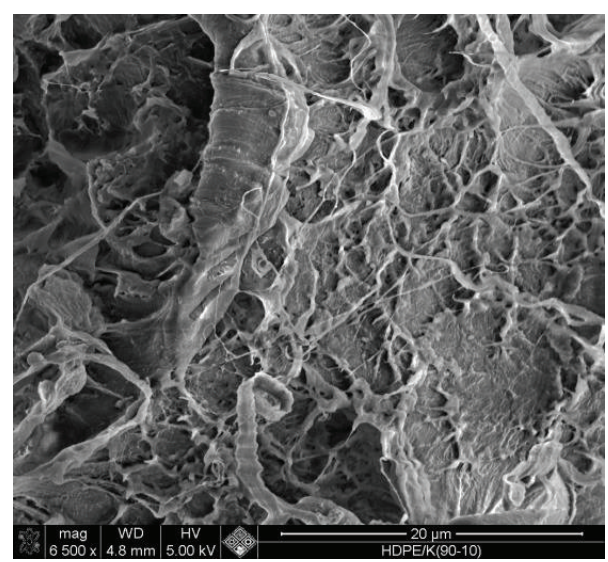

(a)

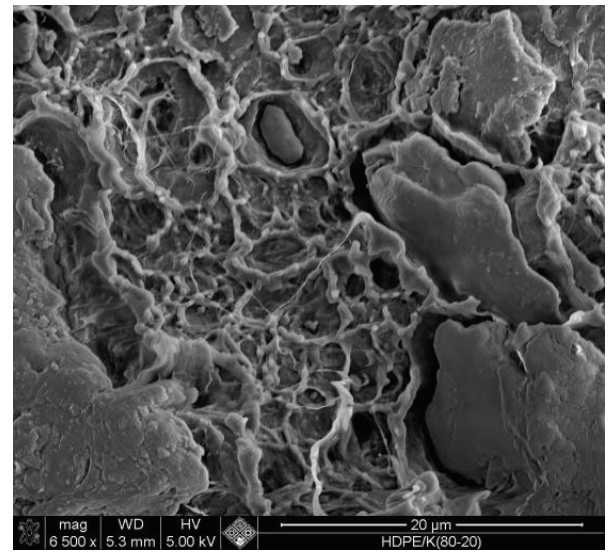

(b)

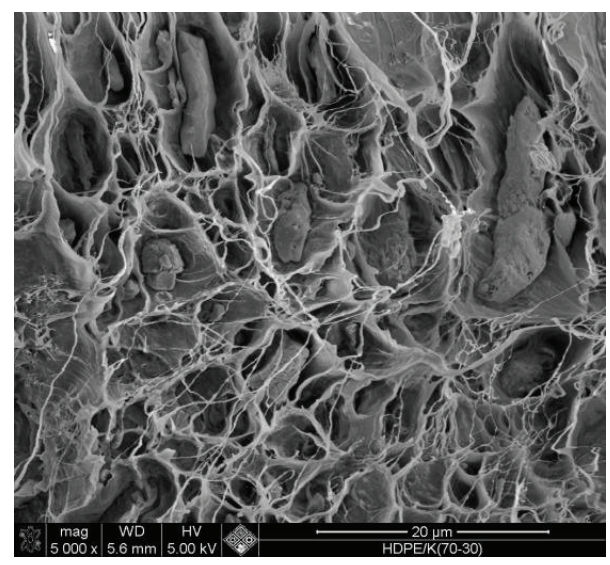

(c)

FIGURE 4: SEM micrographs of the fracture surfaces of the Izod samples for the HDPE/K composites at various loadings of date pits. (a) $10 \mathrm{wt} \%$, (b) $20 \mathrm{wt} \%$, and (c) $30 \mathrm{wt} \%$.

Izod samples of HDPE/S composites which seemed different from that observed with HDPE/K. Here, in Figure 5, date pits size appears smaller and regular despite the debonding of some particles as shown in Figure 5(c). This might explain the improvement in IIS for HDPE/S composites in contrast with that of the HDPE/K composites as reported by our previous

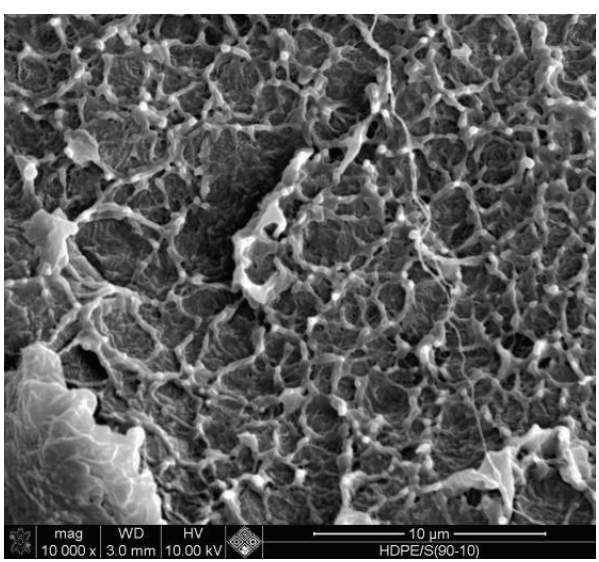

(a)

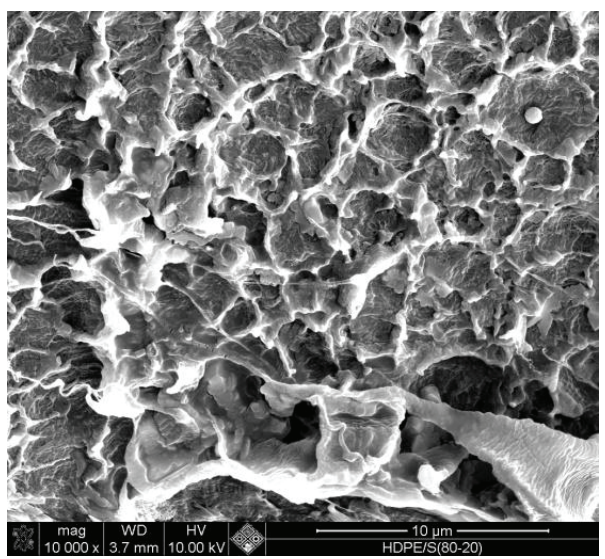

(b)

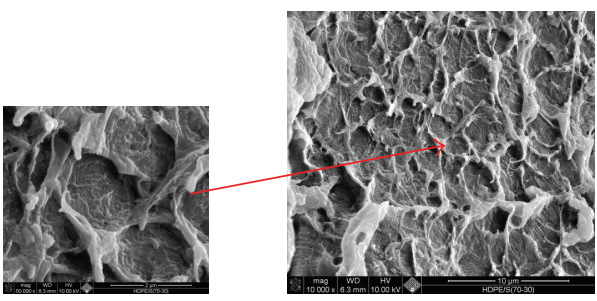

(c)

Figure 5: SEM micrographs of the fracture surfaces of the Izod samples for the HDPE/S composites at various loadings of date pits. (a) $10 \mathrm{wt} \%$, (b) $20 \mathrm{wt} \%$, and (c) $30 \mathrm{wt} \%$.

study [5]. Seeking a plausible explanation for the reduction in IIS for the PS100/date pits composites [5], representative microfracture surfaces of the Izod specimens of PS100/S and PS100/K loaded with $30 \mathrm{wt} \%$ of date pits, shown in Figure 6, were investigated. We can see that although the adhesion between the dispersed phase, that is, date pits, and the matrix, that is, PS100, seems to be visually good, the reduction in the IIS values occurred [5]. We believe that the reason for this reduction may be rooted to the bad distribution and large domain size of date pits within the polymer matrix as clearly seen in Figure 6. 


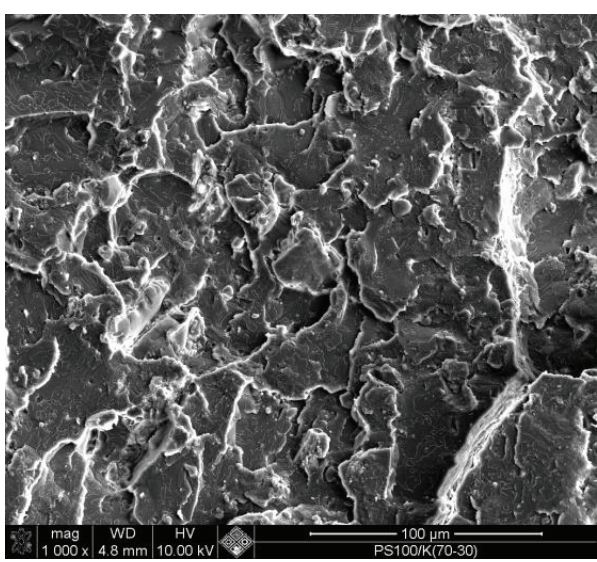

(a)

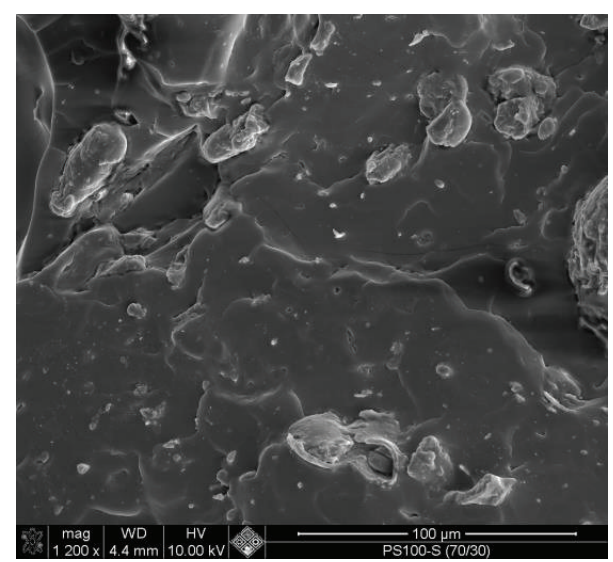

(b)

FIGURE 6: SEM micrographs of the fracture surfaces of the Izod samples for the PS100 composites at 30 wt\% loading of date pits. (a) PS100/K and (b) PS100/S.

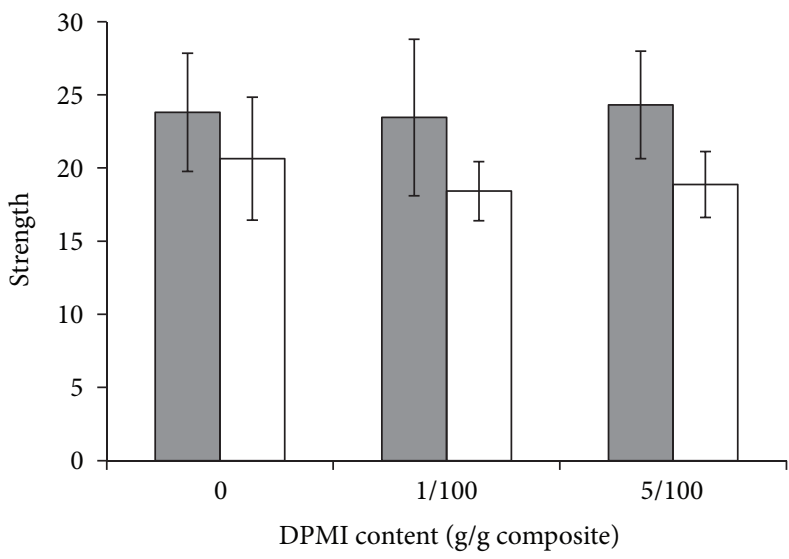

(a)

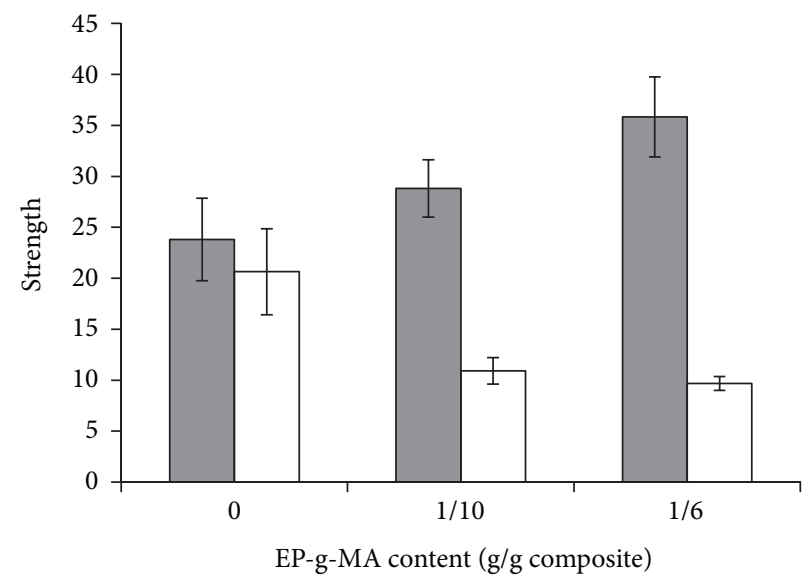

Izod impact $(\mathrm{J} / \mathrm{m})$

$\square$ Tensile (Mpa)

(b)

FIgURE 7: Strength of the PS100 with $30 \mathrm{wt} \% \mathrm{~K}$ date pits with two coupling agents; (a) DPMI and (b) EP-g-MA.

Polystyrene has very low toughness, that is, resilience, in comparison with that of the polyethylene. Furthermore, the resilience of the polystyrene is anticipated to deteriorate upon incorporating additives and fillers as this was already shown by our previous study [5]. For this reason, we chose to use PS100/date pits composite system to show the effect of coupling agents on altering the morphology of the fracture surfaces of the composites and hence the mechanical properties may be improved. Figure 7 shows the strength of the PS100/K (70/30 wt\%) composites in the presence of two coupling agents; DPMI and EP-g-MA. Figure 7(a) shows that DPMI at a concentration of $5 \mathrm{~g}$ per $100 \mathrm{~g}$ of neat composite slightly increases the IIS of the composites, while a small decrease in the TS of the composites was observed. On the other hand, small amounts of EP-g-MA, for example, $1 \mathrm{~g}$ per $10 \mathrm{~g}$ of the neat composite, have led to a remarkable increase in IIS as shown in Figure 7(b). Nevertheless, TS of the composite was reduced to $50 \%$ upon the addition of up to $1 \mathrm{~g}$ of EP-g-MA per $6 \mathrm{~g}$ of neat composites. This is expected since rubbers and elastomers have very low values of modulus. This finding may be put in the frame of structure or morphology-property relationships. In other words, one should link the properties to the appearance and distribution of the dispersed phase in the composite matrix. Figure 8 shows a comparison of the fracture surface morphologies of the neat composite, that is, PS100/K (70/30 wt\%), with that of the same composite but in the presence of DPMI and EP-g-MA. One can clearly see, from Figures 8(a) and 9(a), that the $\mathrm{K}$ particles appear large and badly distributed within the PS100 matrix. In contrast, Figures 8(b) and 9(b) show the fine distribution of smaller K particles within the PS100 matrix upon coupling with small amount of DPMI. Lastly, 


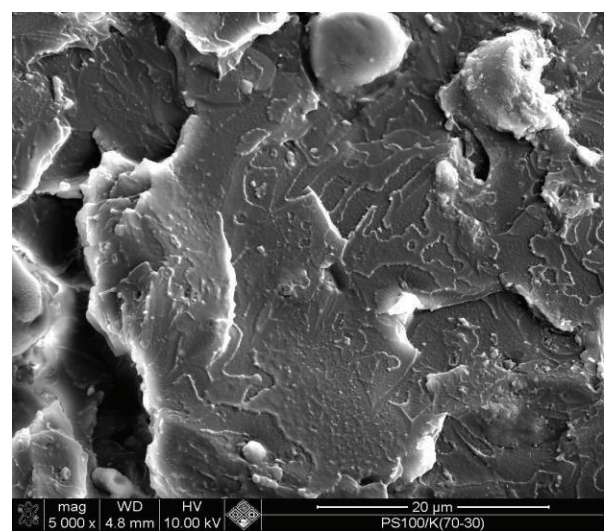

(a)

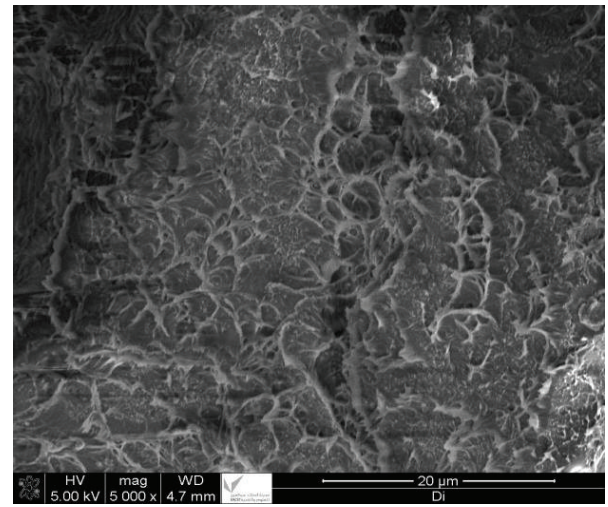

(b)

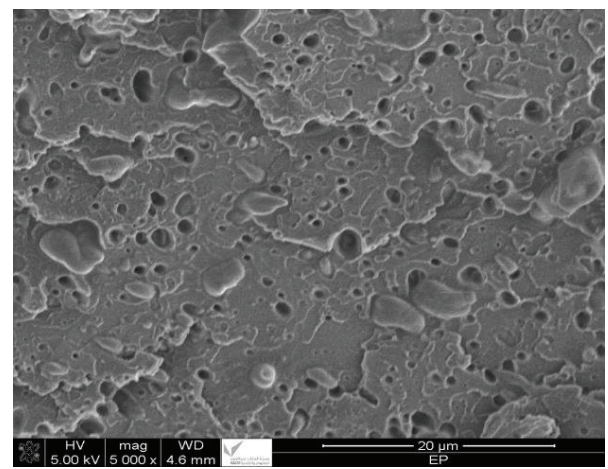

(c)

FIGURE 8: SEM micrographs of PS100/K (70/30 wt\%) with (a) $0 \%$ coupling agent; (b) 1/30 diphenylmethane (PS/K); (c) 1/6 EP-g-MA (PS/K).

Figure 8(c) shows different morphology, in comparison with that of the neat composite, where the dispersed domains appeared smaller and rubber phase appears as elongated particles with a good sign of adhesion into the composite matrix which explains the improvement on the resilience of the composites as shown in Figure 7(b).

\section{Conclusion}

Polymer/date pits composites modified with two coupling agent systems, that is, DPMI and EP-g-MA, were prepared

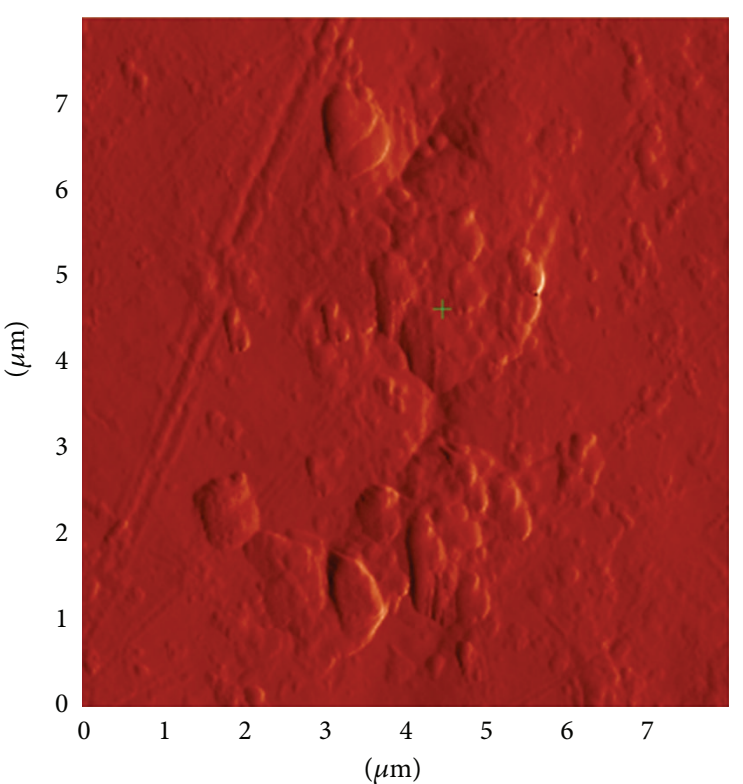

(a)

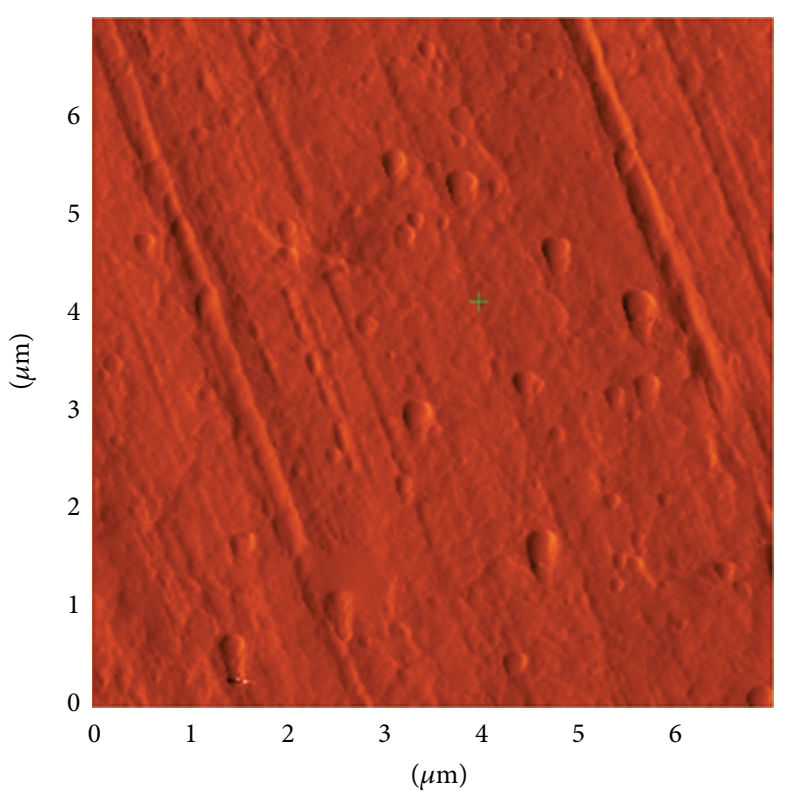

(b)

FIGURE 9: SPM micrographs for PS100/K (70/30 wt\%) coupled with DPMI; (a) 0\% and (b) 5/100 (g DPMI/g neat composite).

and tested mechanically and morphologically. Polymeric matrices used were HDPE and PS. In the absence of proper coupling agent systems, fracture surfaces of the polymer/date pits composite systems tested in this study were rough with great degree of debonding and bad adhesion of date pit particles which appeared to be very large. Both coupling agents used in this study, DPMI and EP-g-MA, were effective in altering the morphology of the polymer/date pits composites and hence improving the mechanical properties. 


\section{Conflict of Interests}

The authors declare that there is no conflict of interests regarding the publication of this paper.

\section{Acknowledgment}

The authors thank king Abdulaziz City for Science and Technology (KACST) for supporting the study.

\section{References}

[1] Z. Wang, E. Wang, S. Zhang, Z. Wang, and Y. Ren, "Effects of cross-linking on mechanical and physical properties of agricultural residues/recycled thermoplastics composites," Industrial Crops and Products, vol. 29, no. 1, pp. 133-138, 2009.

[2] H.-S. Yang, H.-J. Kim, H.-J. Park, B.-J. Lee, and T.-S. Hwang, "Effect of compatibilizing agents on rice-husk flour reinforced polypropylene composites," Composite Structures, vol. 77, no. 1, pp. 45-55, 2007.

[3] Y. Lei, Q. Wu, F. Yao, and Y. Xu, "Preparation and properties of recycled HDPE/natural fiber composites," Composites A, vol. 38, no. 7, pp. 1664-1674, 2007.

[4] A. Karmarkar, S. S. Chauhan, J. M. Modak, and M. Chanda, "Mechanical properties of wood-fiber reinforced polypropylene composites: effect of a novel compatibilizer with isocyanate functional group," Composites A, vol. 38, no. 2, pp. 227-233, 2007.

[5] F. D. Alsewailem and Y. A. Binkhder, "Preparation and characterization of polymer/date pits composites," Journal of Reinforced Plastics and Composites, vol. 29, no. 11, pp. 1743-1749, 2010.

[6] A. Ghazanfari, S. Emami, S. Panigrahi, and L. G. Tabil, “Thermal and mechanical properties of blends and composites from HDPE and date pits particles," Journal of Composite Materials, vol. 42, no. 1, pp. 77-89, 2008.

[7] J. S. Mossa, M. S. Hifnawy, and A. G. Mekkawi, "Photochemical and biological investigation on date seeds (Phoenix dactylifera L.) produced in Saudi Arabia," Arab Gulf Journal of Science and Research, vol. 4, no. 2, pp. 495-507, 1986.

[8] M. S. Rahman, S. Kasapis, N. S. Z. Al-Kharusi, I. M. Al-Marhubi, and A. J. Khan, "Composition characterisation and thermal transition of date pits powders," Journal of Food Engineering, vol. 80, no. 1, pp. 1-10, 2007. 

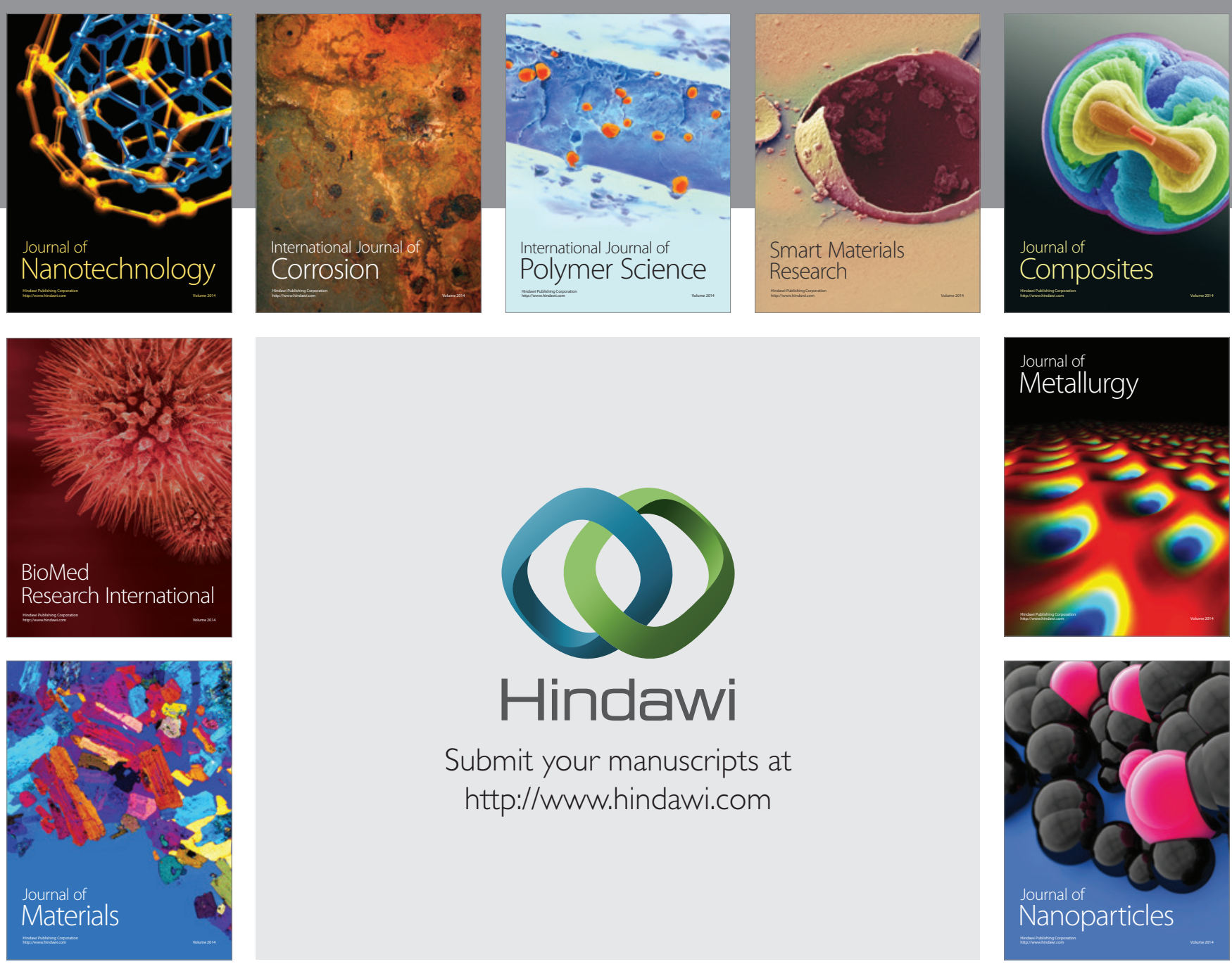

Submit your manuscripts at http://www.hindawi.com
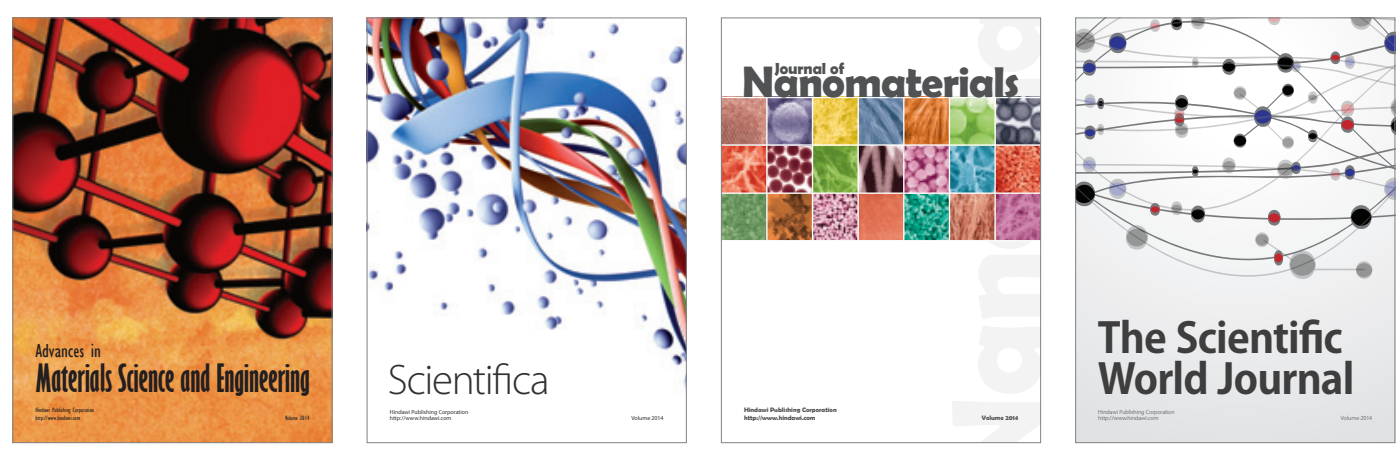

\section{The Scientific World Journal}
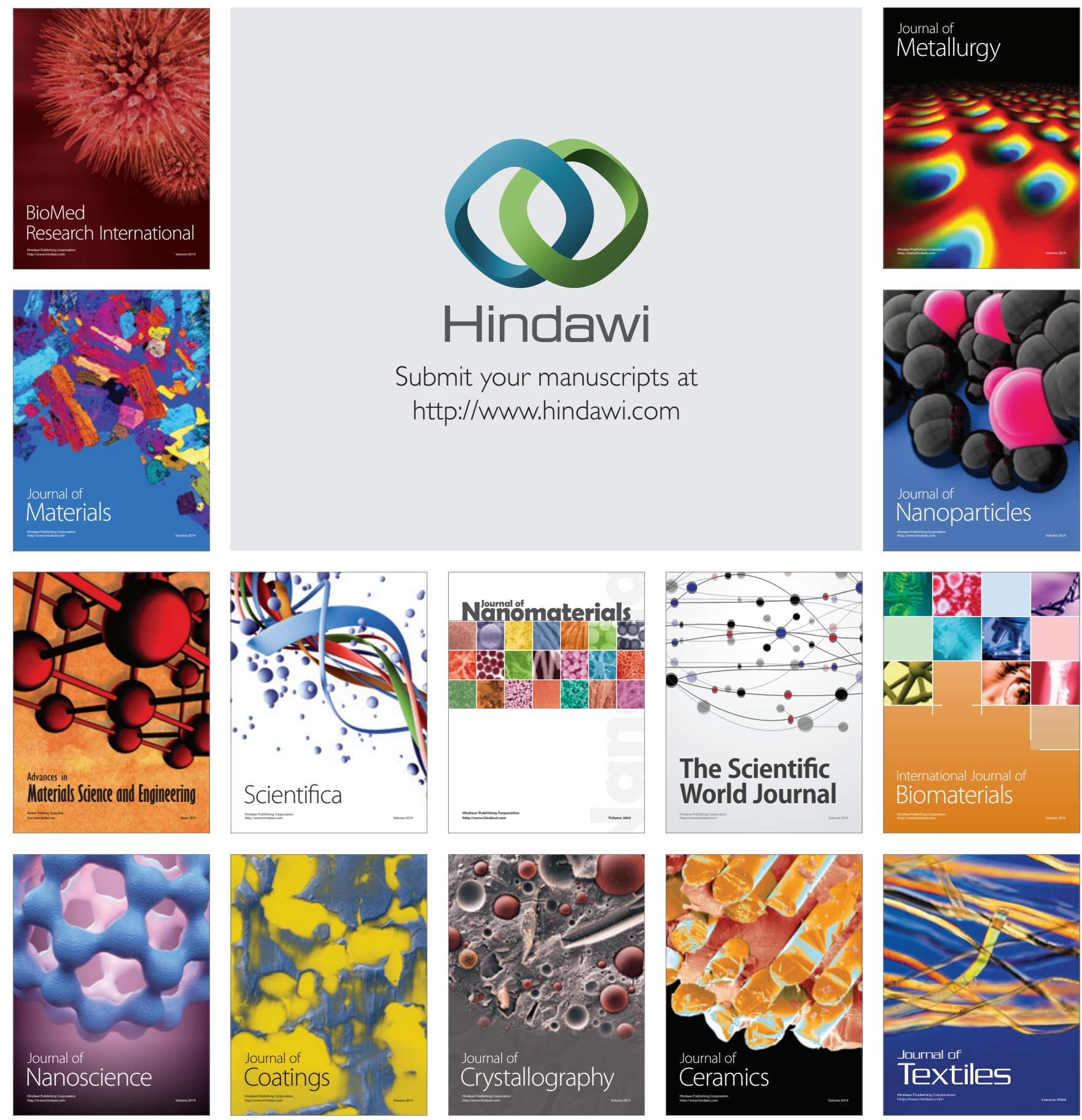